\title{
Asymmetric Fuzzy Logic Controlled DC-DC Converter for Solar Energy system
}

\author{
Mohamed Boutouba*, Abdelghani El Ougli*, Sabah Miqoi* And Belkassem Tidhaf* \\ * ENSA Oujda, Faculty of Science, UMP Oujda Morocco. \\ E-mail: btba.med@gmail.com
}

\begin{abstract}
In this paper, a controlled voltage system for a solar energy source is presented by a new command called fuzzy logic controller (FLC) via a DCDC converter. The fuzzy logic control is selected due its performance and efficiency even for nonlinear systems such as the DC-DC converters.
\end{abstract}

A simulation with MATLAB SIMULINK environment of the FL control system, compared with a classical PI controller, is presented at the end of the paper to illustrate the good behavior of the control.

Keywords - Buck and Boost converter, PI Fuzzy logic controller (FLC), photovoltaic (PV), voltage regulation.

\section{INTRODUCTION}

Adaptation of the voltage and current between sources and loads is the main task of DC-DC converters. They are used in many different industry applications due to the advantage of low power loss and best yield; therefore their studies have become more interesting in recent years.

Because of nonlinearity of DC-DC converters, conventional techniques of linearization remain unable to describe and control the system, this results in reducing the system performance or instability. To solve this problem, an approach of a fuzzy logic control has been proposed as an alternative solution for non-linear system whose linearization is hard to find.

The studied system is powered by a photovoltaic voltage source along with using different kinds of loads, as shown in Fig. 1.

For photovoltaic source energy, the level of production energy is unstable and unpredictable because it depends on the level of irradiation and temperature.

This has the effect of changing the solar panel voltage and then the output voltage (at the load). To ensure the stability of the desired output voltage, a regulation block is needed as an intermediary between the panel and the load. The Fuzzy logic control for DC-DC converters, which is the goal of this work, will intervene to keep the output to the given value even if the load, the input voltage or the desired voltage change.

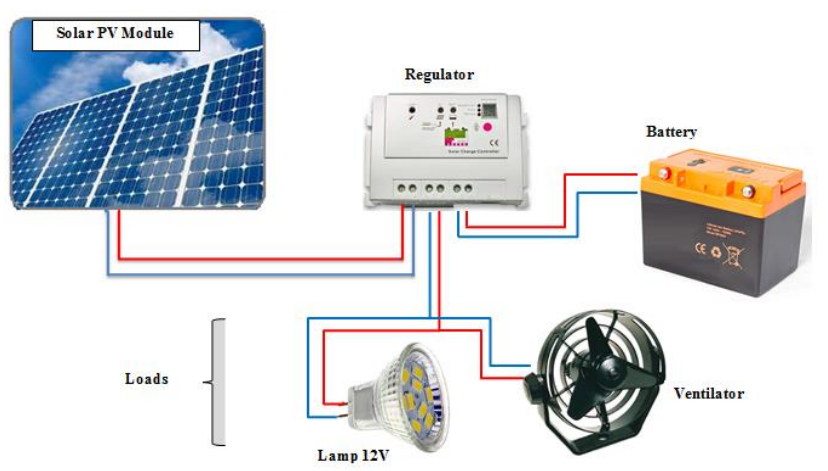

Fig .1. PV supply voltage for various loads.

The purpose of this process control is to maintain the state of a physical or electrical quantity stable, without human intervention, for a desired given value called the set point, per share on a manipulated variable.

The Fig. 2 presents the general block of a control system: 


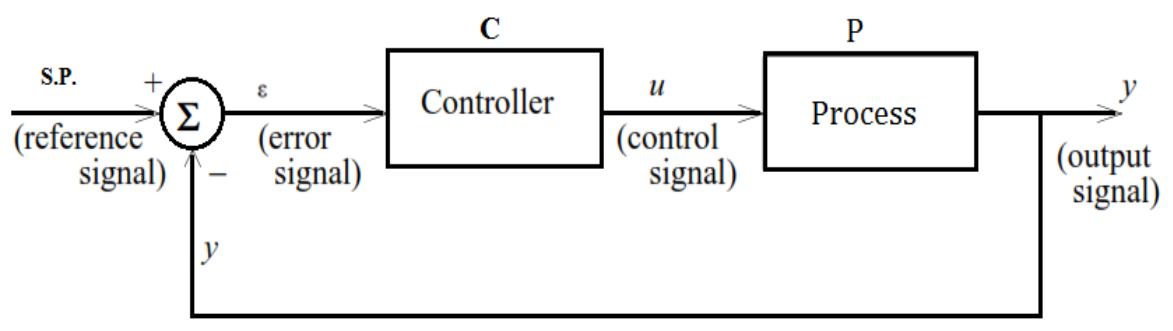

Fig .2. Block diagram of a controller process.

Where:

- $\quad$ S.P. : Set point, it is the desired output signal, also called reference (a voltage in proposed case).

- $\quad \boldsymbol{C}$ : is the controller or corrector, namely the block that allows the control of the output voltage.

- $\boldsymbol{P}$ : process to control; a DC-DC converter in proposed case.

- $\varepsilon:$ It is the error between the Set point (SP) and the measured value of the output y: $\varepsilon=S P-y$.

- $u$ : The control signal generated by the controller.

The block calculates an error value that is equal to the difference between the measured process variable and the desired set point. The controller attempts to minimize the error by adjusting the process through the use of a manipulated variable: the control signal.

\section{BUCK AND BOOST CONVERTER SYSTEM DESCRIPTION:}

Fig. 3 shows the electronic circuit of the Buck and Boost converter. A resistive load that is called $R_{C h}$ is used, the output as $V_{\text {out }}$, and the set point or reference voltage as $V_{r e f}$.
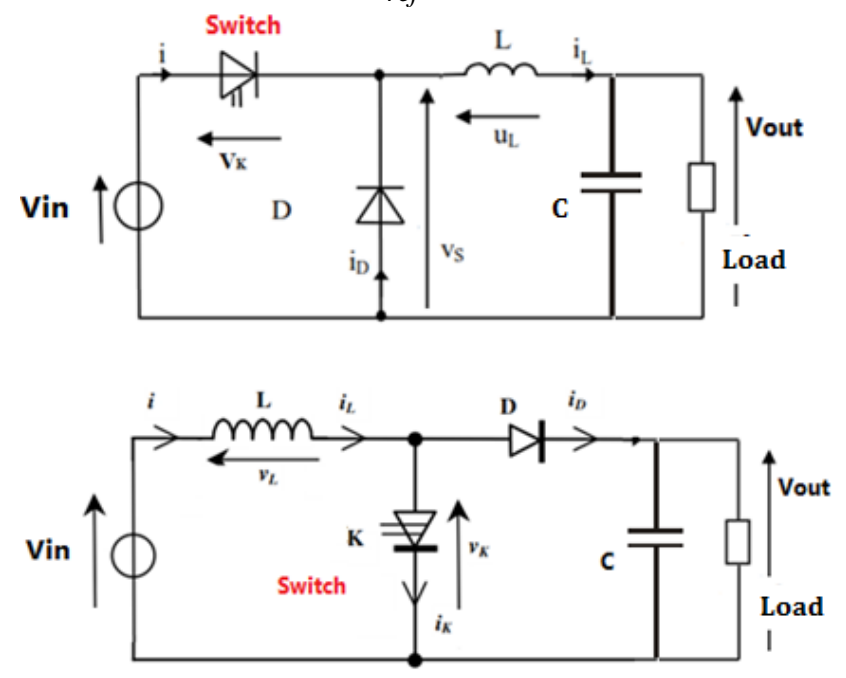

Fig .3. Topology of the buck and Boost converter respectively.
The electronic switch is controlled by a PWM signal (Pulse Width Modulation) whose duty cycle $\alpha=t_{O N} / T$.

- $t_{O N}$ is the time with which the switch is on, and $T$ represents the period of the switch control signal.

The circuit equations are written as bellow

$\left\{\begin{array}{l}V_{\text {out }}=\alpha \cdot V_{\text {in }} \\ I_{\text {out }}=\frac{I_{\text {in }}}{\alpha}\end{array} \quad\right.$ for Buck converter

$\left\{\begin{array}{l}V_{\text {out }}=\frac{V_{\text {in }}}{1-\alpha} \\ I_{\text {out }}=(1-\alpha) \cdot I_{\text {in }}\end{array} \quad\right.$ for Boost converter

From the equations it becomes clear that it is possible to control the output voltage of a PWM signal whose duty cycle is variable according to the need.

The inductance is used for smoothing the chopped current that crosses it, thus reducing the ripple; it must have an induction factor greater than a critical value to ensure continuous conduction, avoid the cancellation of the current and guarantee the proper functioning of the circuit.

The critical value is calculated with $\alpha=0.5$ when the ripple current is maximum $\Delta i_{L}(\max )$

$$
L \geq L_{\min }=\frac{V_{\text {in }}}{4 f \Delta i_{L}(\max )}
$$

- $\quad f$ : Switching frequency.

\section{CONTROL SYSTEM}

The use of traditional corrector: proportional, integral and derivative , denoted $\mathrm{P}, \mathrm{I}$, and $\mathrm{D}$ to control a system is effective, but stay ineffective in front of the 
nonlinear system whose study becomes more complex. That is why this method is generally recommended for linear systems of which it is possible to describe in equations.

DC-DC converters have this problem of nonlinearity hence the interest to seek an alternative to these traditional correctors: a fuzzy logic controller (FLC), a relevant strategy offering outstanding performance and an interesting alternative approach such a raisonnement similar to that of man, and to manage complex systems intuitively.
Fuzzy logic allows reasoning not on numeric variables, but on linguistic variables, i.e., on qualitative variables (large, small, medium, far, near, etc.). The fact of reasoning about these linguistic variables will allow manipulating knowledge in natural language. The only thing which can be introduced in the system is what is called inference rules which are expressed in natural language.

As shown in Fig. 4, the fuzzy logic controller block is divided into three sub block: Fuzzification, fuzzy inference engine with rules, and defuzzification.

\section{A. PI Fuzzy logic controller}

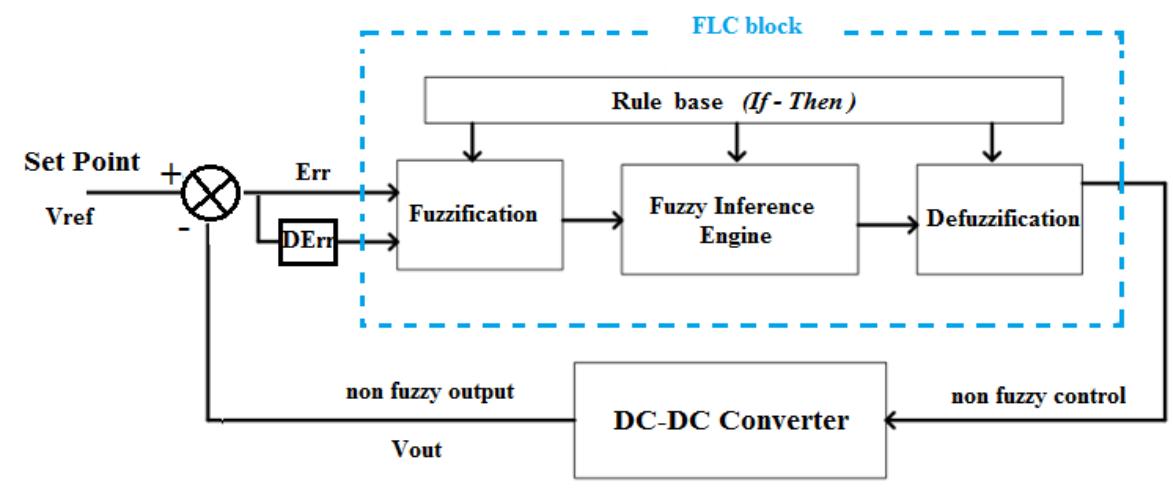

Fig .4. Block diagram of a PI fuzzy controller

\section{B. Fuzzification}

The input and output variables chosen to model the system are numerical quantities. The fuzzification step is to transform the actual magnitudes linguistic variables for an inference processing. Thus, for each input and output variable there are associated sets, characterizing the linguistic terms taken by these variables. These terms will be used to write the rules of inference.

The linguistic variables -as shown in Fig. 5- are modeled in the form of a function, called membership function; the choice of the form is arbitrary. The most frequently used fuzzy control shape is the triangular shape.

In this paper, a PI controller has been used, it has as inputs: the error and the change of error:

$E=\varepsilon=V_{\text {ref }}-V_{\text {out }}$

$D E=\Delta \varepsilon=\varepsilon(t)-\varepsilon(t-1)$

Seven memberships for each input and output are used (Asymmetric ones for input "error" and the output), where $N$ and $G$ mean negative and positive. $B, M, S$ And $Z O$ are respectively: Big, Medium, Small and Zero.
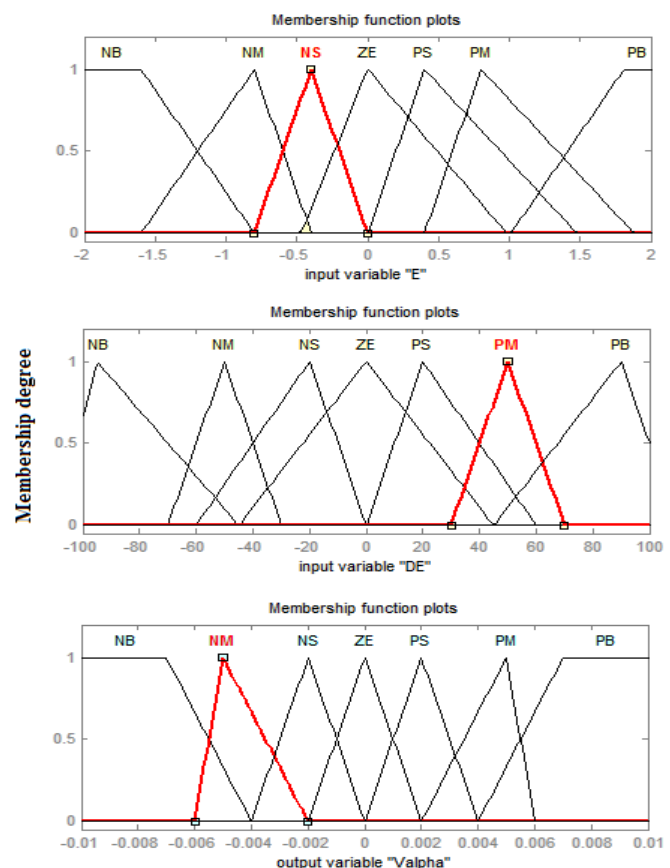

Fig .5. Variables inputs/output linguistic 


\section{Rules base}

A fuzzy rule base is a collection of rules that allows linking the fuzzy variables of input and output. The description of the control is via these rules; it has the following form:

- If $E$ is $N S$ and DE is PM, then dValpha is NM.

Corresponds to: If the error is negative and the error variation is fairly large, then the duty cycle will be decreased.

These rules can be presented as in Table 1. A graphic view of output response according to the inputs is shown in Fig. 6.

\section{Fuzzy inference engine}

It allows calculating the fuzzy set associated with the command, and is done with fuzzy inference operations and rules aggregation. For each rule, the fuzzy inference is based on the use of a fuzzy implication operator.

This operator quantifies the binding strength between the premises and the conclusion of the rules.

There are many ways to express inferences: by linguistic description, matrix or array of inference.

Mamdani's fuzzy inference method is the most commonly used and is based on the recovery of the minimum value of the degrees of membership of the input variables. It allows calculating the fuzzy set associated with the command and is done with fuzzy inference operations and rules aggregation.

Consider the previous example:

$\mu_{\mathrm{NM}}\left(\mathrm{V}_{\alpha}\right)=\min \left(\mu_{\mathrm{NS}}(\varepsilon), \mu_{\mathrm{PM}}(\Delta \varepsilon)\right)$

Table 1. Fuzzy rules

\begin{tabular}{|c|c|c|c|c|c|c|c|}
\hline \multirow{2}{*}{$\mathbf{D E}$} & \multicolumn{7}{|c|}{$\mathbf{E}$} \\
\cline { 2 - 8 } & $\boldsymbol{N B}$ & $N \boldsymbol{M}$ & $\boldsymbol{N S}$ & $Z \boldsymbol{E}$ & $P S$ & $P \boldsymbol{M}$ & $\boldsymbol{P B}$ \\
\hline $\mathbf{N B}$ & $Z E$ & $Z E$ & $Z E$ & $P S$ & $P M$ & $P B$ & $P B$ \\
\hline $\mathbf{N M}$ & $N S$ & $Z E$ & $Z E$ & $P S$ & $P M$ & $P B$ & $P B$ \\
\hline $\mathbf{N S}$ & $N M$ & $N S$ & $N S$ & $Z E$ & $P S$ & $P M$ & $P B$ \\
\hline $\mathbf{Z E}$ & $N B$ & $N M$ & $N S$ & $Z E$ & $P S$ & $P S$ & $P B$ \\
\hline $\mathbf{P S}$ & $N B$ & $N M$ & $N S$ & $N S$ & $Z E$ & $P S$ & $P M$ \\
\hline $\mathbf{P M}$ & $N B$ & $N B$ & $N M$ & $N S$ & $P S$ & $Z E$ & $P M$ \\
\hline $\mathbf{P B}$ & $N B$ & $N B$ & $N B$ & $N B$ & $P S$ & $Z E$ & $Z E$ \\
\hline
\end{tabular}

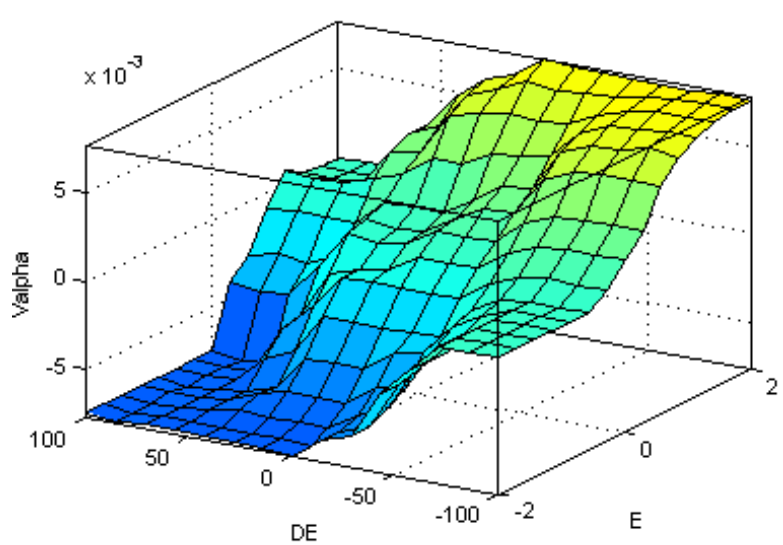

Fig .6. Control Surface View.

\section{E. Defuzzification}

After the inference step, the overall result is a fuzzy value. This result should be defuzzifed to obtain a final crisp or non-fuzzy output. There are several defuzzification methods to achieve, such as: the mean of maxima, the center of areas, and the center of maxima.

Center of gravity (area) is the most prevalent and physically appealing of all the defuzzification methods.

The general expression of the center of area is given by the equation:

$$
d V_{\alpha}=\frac{\sum_{i} \mu(x(i)) \cdot x(i)}{\sum_{i} \mu(x(i))}
$$

- $\quad x(i)$ : Output variable equivalent to $d V_{\alpha}(i)$

- $\mu(x(i))$ : Membership degree for sampled value of the output.

- $\quad i$ : Sample of the interval of the output variable.

The obtained signal is defined by the following relationship:

$V_{\alpha}(t)=V_{\alpha}(t-1)+d V_{\alpha}$

It is an analog signal which is incremented or decremented by the output of the FLC controller $d V_{\alpha}$. The signal is proportional to the desired duty cycle.

Another block comes after to convert the output signal in a PWM signal via a comparator block with a sawtooth signal, to order and control DC-DC converter as shown in Fig. 7. 


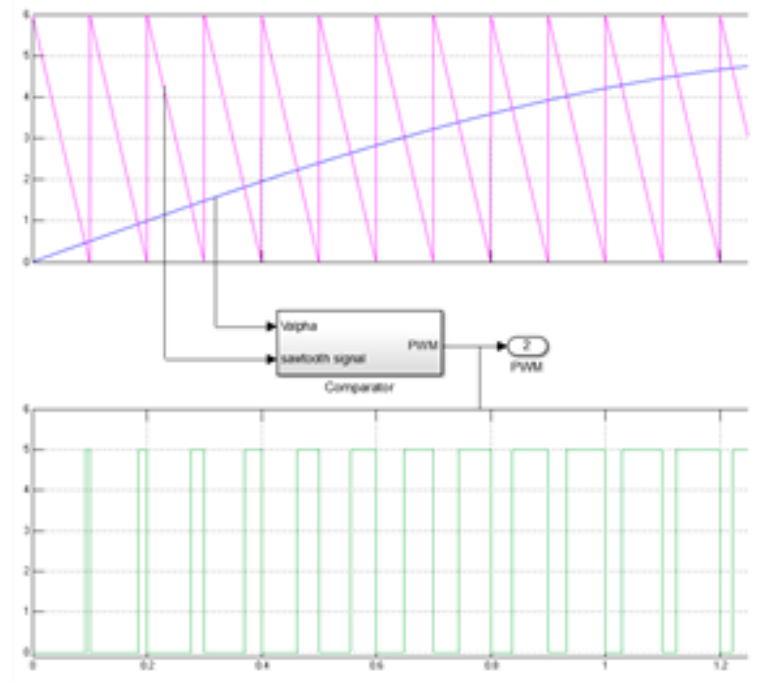

Fig .7. PWM signal generator.

\section{SIMULATION RESULT OF BUCK CONVERTER WITH FLC ON MATLAB SIMULINK}

The complete circuit studied in this article using the MATLAB SIMULINK is shown in Fig. 8.

The simulation parameters used in these simulations are shown in Table 2:

\begin{tabular}{|l|l|}
\hline Switching Frequency & $f=10 \mathrm{KHz}$ \\
\hline Filter Inductance & $H=4 m \mathrm{H} \quad$ with $\quad r_{L}=2 m \Omega$ \\
\hline Filter Capacitance & $C=560 \mu \mathrm{F}$ \\
\hline $\begin{array}{l}\text { Kp and Ki for the FL } \\
\text { control are respectively }\end{array}$ & $0.0125 ; 0.067$ \\
\hline
\end{tabular}

To verify the proper functioning of the control system by fuzzy logic, several simulations were processed and compared with a classical PI control, in presence of modification of some variables.

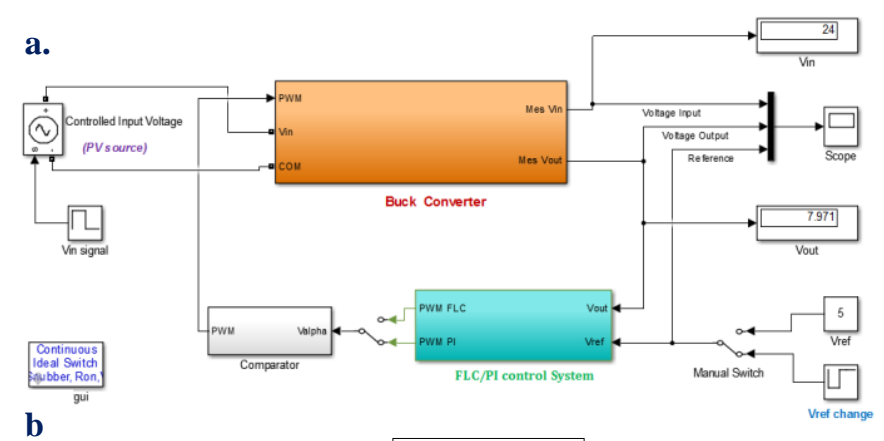

b

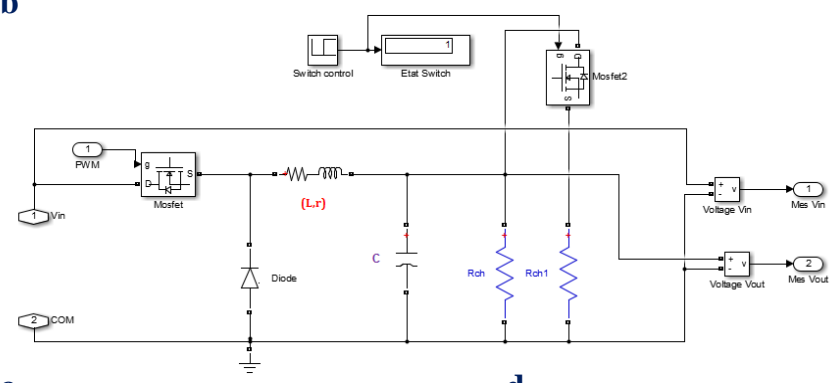

c.
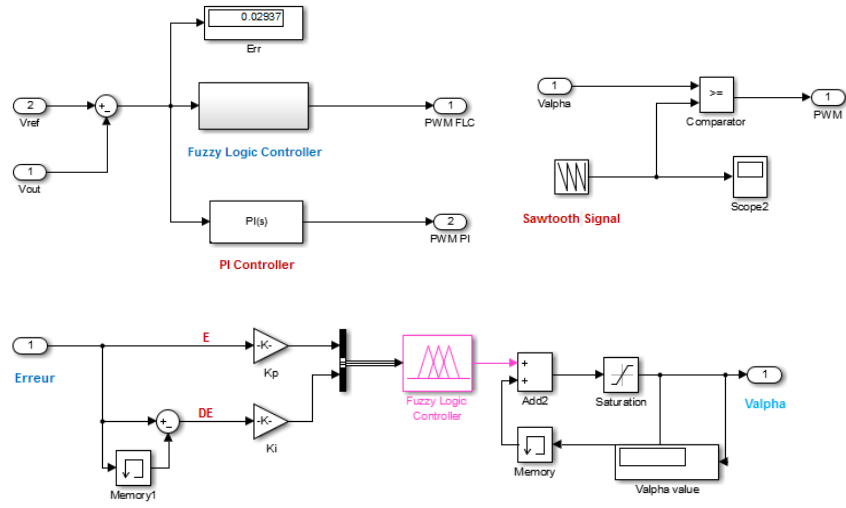

Fig .8. a. Buck converter with FLC/PI controller.

b. Buck converter topology.

c. FLC and PI block controller.

d. PWM generator.

e. FLC structure.

A. Speed pursuit of the reference voltage (set point) in presence of an irregular voltage source

For this simulation the load is fixed to $R_{c h}=10 \Omega$, reference voltage to $V_{\text {ref }}=5 \mathrm{~V}$. The circuit is powered by a voltage variable in time as follows:

$$
V_{i n}=\left\{\begin{array}{lc}
24 V & 0 \leq t \leq 0.5 s \\
20 V & t>0.5 s
\end{array}\right.
$$

The result in Fig. 9 shows the evolution of the output voltage and its pursuit to the set point (reference voltage) for the two control commands. 


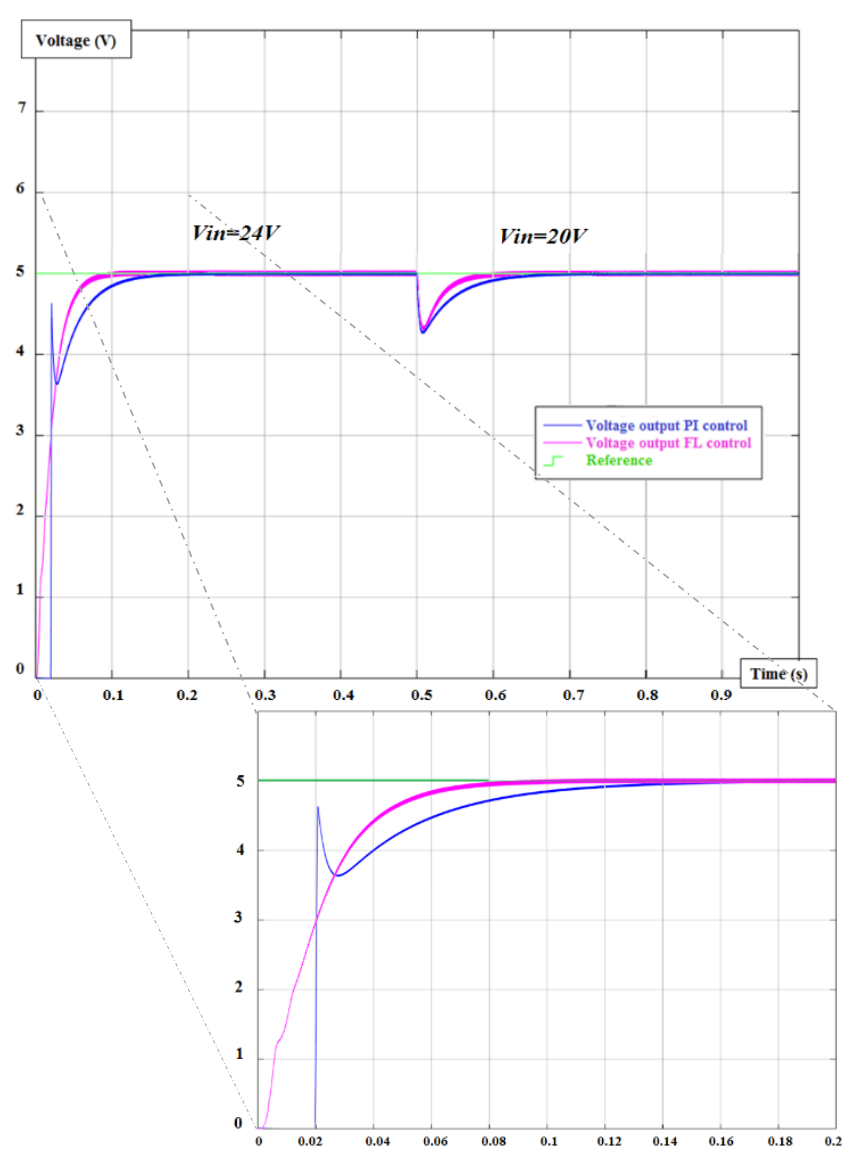

Fig .9. Simulation with irregular supply voltage.

As shown, the response time for the fuzzy-PI control compared with the classical one is better: respectively $0.1 s$ against $0.15 s$.

At $t=0.5 \mathrm{~s}$, the input voltage drop from $24 \mathrm{~V}$ to $20 \mathrm{~V}$ causes a loss of voltage output. Quickly, the FLC changes the duty cycle to correct the error, and then brings back the output voltage to the desired value for a reduced response time $t_{r}<0.1 s$ for the FLC against $0.15 s$ for the classical PI control.

\section{B. Variable set point pursuit}

In this second simulation, the simulation parameters are given as follows:

$$
\begin{array}{r}
V_{i n}=24 V \text { and } R_{c h}=10 \Omega \text { with a reference voltage } \\
V_{\text {ref }}=\left\{\begin{array}{cc}
5 V & 0 \leq t \leq 0.5 s \\
8 V & t>0.5 s
\end{array}\right.
\end{array}
$$

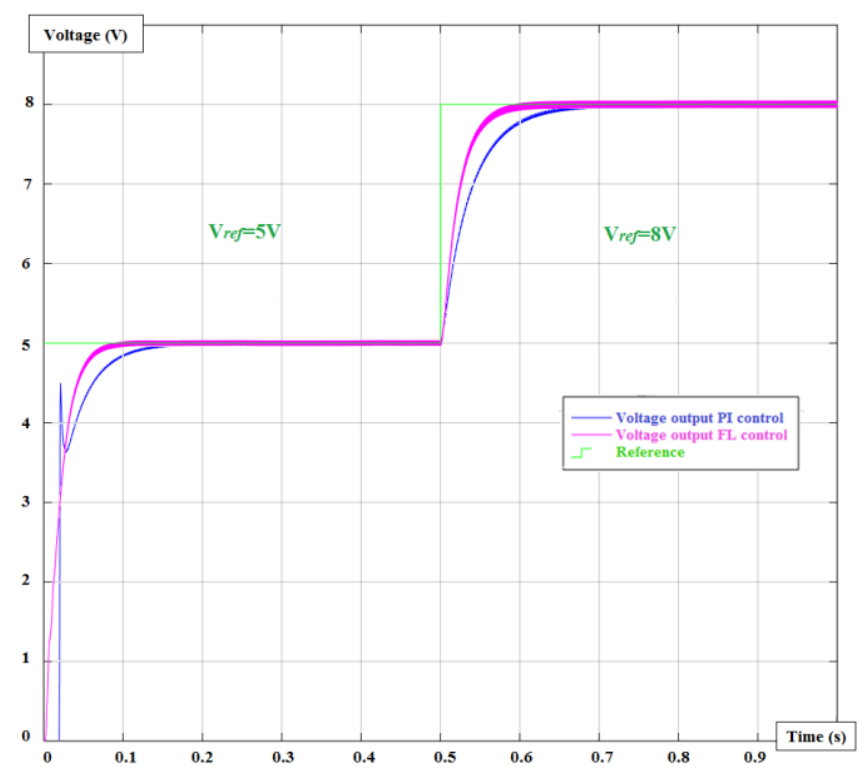

Fig .10. Simulation with variable set point.

Fig. 10 shows again the pursuit of the fuzzy system even if the set point changes during the simulation, the output voltage follows the new set point once it is changed.

\section{Simulation with a variable load}

The output voltage for a control process has to be independent of the choice of the load. The system should keep at any instant the output voltage close to the set point even when the load changes.

It is the case of the studied control system: during the simulation, whose result is presented in Fig. 11, at $t=0.5 \mathrm{~s}$ the load changes from $R_{c h}=10 \Omega$ to $5 \Omega$.

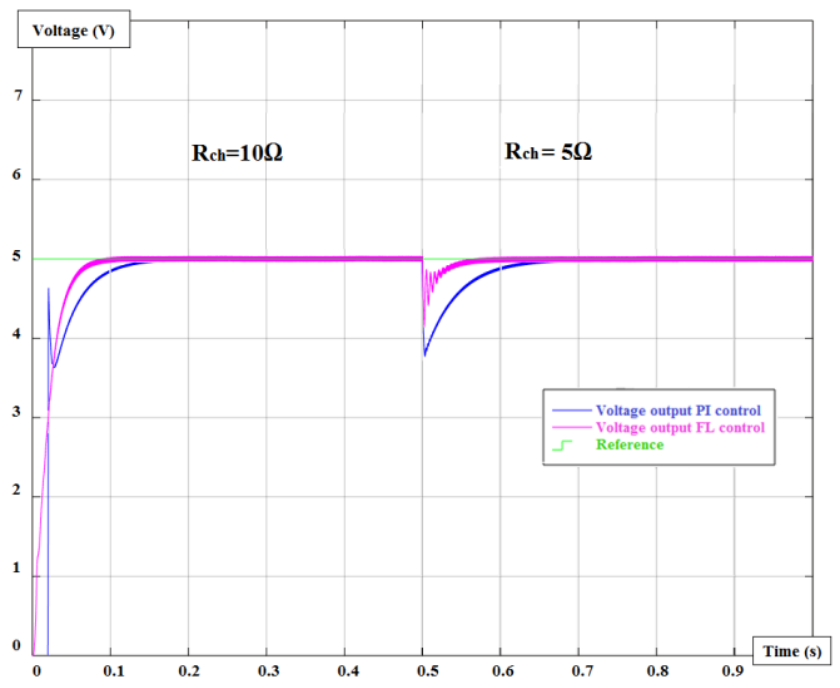

Fig .11. System Response with a variable Load. 
It is concluded that, the PI-Fuzzy control guarantees the pursuit of the set point voltage in a reduced time compared to the conventional PI control.

\section{Precision}

Among the major points in the regulatory system is the precision. A system whose output is far from the set point is considered nonfunctional. The system presents the study advantage to have a reinforced precision as shown in Fig. 12, case of $V_{i n}=24 \mathrm{~V}$ and $R_{c h}=10 \Omega$.

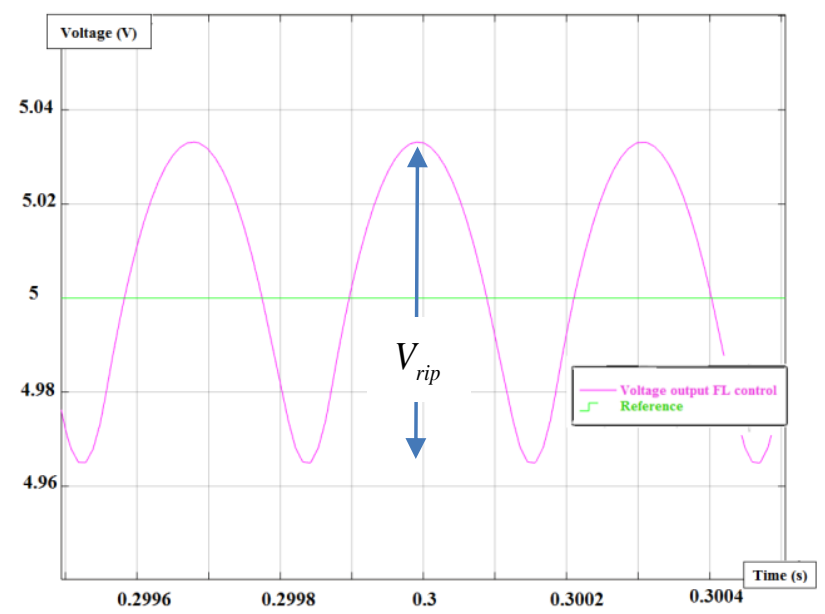

Fig .12. Output voltage ripple.

According to the figure, the ripple rate is given by:

$\eta=V_{\text {rip }} /$ Vref $=35 \times 10^{-3} / 5=0.7 \%$

Too low rate means better precision.

\section{v. CONCLUSION}

In this paper, an alternative of an order for voltage regulation via a DC-DC converter was proposed, powered by an irregular source voltage as photovoltaic.

To illustrate the work, several simulations were treated under MATLAB SIMULINK environment for a Buck converter equipped with a Fuzzy PI Controller (FLC) against a classical PI control. The analysis given can extend this work to other converters (boost converter, buck-boost converter, etc.).
The obtained results strongly confirm the effectiveness of the proposed control process system, which has both: high precision and a set point tracking speed.

\section{REFERENCES}

[1] Cetin Elmas, Omer Deperlioglu, Hasan Huseyin Sayan, "Adaptive fuzzy logic controller for DCDC converters", Expert Systems with Applications, Vol 36, Issue 2, Part 1, March 2009, pp. 1540-1548. ISSN 09574174.

[2] First K.V.Hari Prasad; Second CH.Uma Maheswar Rao; Third A.Sri Hari; Dept. of Electrical Engineering, Vignan University. "Design and simulation of a fuzzy logic controller for buck \& boost converters," International Journal of Advanced Technology \& Engineering Research (IJATER). Vol. 2, Issue3. MAY 2012, pp. 218-224, ISSN 2250-3536.

[3] Dr.T.Govindaraj, Rasila R, Muthayammal Engineering College, Rasipuram, Tamil Nadu, India. "Development of fuzzy logic controller for DC - DC buck converters," Int J Engg Techsci Vol. 2, no.2 2011, pp. 192-198.

[4] Sahin, M.E. ; Dept. of Phys., Univ. of Rize, Rize, Turkey ; Okumus, H.I. "Fuzzy logic controlled buck-boost DC-DC converter for solar energybattery system," Innovations in Intelligent Systems and Applications (INISTA), 2011 International Symposium on. 15-18 June 2011 IEEE, pp. $394-397$.

[5] Cheng-Shion Shieh, "Fuzzy PWM based on Genetic Algorithm for battery charging," Applied Soft Computing, Vol. 21, August 2014, pp. 607616, ISSN 1568-4946.

[6] Mamun Rabbani, Student Member IEEE, H. M. Mesbah Maruf, Tanvir Ahmed, Md. Ashfanoor Kabir, Member IEEE, y Upal Mahbub, Bangladesh University of Engineering and Technology. "Fuzzy logic driven adaptive PID controller for PWM based buck converter," IEEE/OSA/IAPR International Conference on Informatics, Electronics \& Vision. 18-19 May 2012. 
[7] Liping Guo, John Y. Hung, R.M. Nelms, "Design of a fuzzy controller using variable structure approach for application to DC-DC converters," Electric Power Systems Research, Vol. 83, Issue 1, February 2012, pp. 104-109, ISSN 03787796.

[8] Ahmad El Khateb, Member, IEEE, Nasrudin Abd Rahim, Senior Member, IEEE, Jeyraj Selvaraj, and M. Nasir Uddin, Senior Member, IEEE. "Fuzzy logic controller based SEPIC converter for maximum power point tracking," IEEE Transactions on industry applications, Vol. 50, Issue 4, Feb 2014, pp. 99.

[9] Augusti Lindiya, S. Palani, Iyyappan, "Performance comparison of various controllers for dc-dc synchronous buck converter," Procedia
Engineering, Vol. 38, 2012, pp. 2679-2693, ISSN 1877-7058.

[10] Chaoui, H.; Miah, S.; Sicard, P., "Adaptive fuzzy logic control of a DC-DC boost converter with large parametric and load uncertainties," Advanced Intelligent Mechatronics (AIM), 2010 IEEE/ASME International Conference on, Montreal, ON, 6-9 July 2010, pp. 575-580.

[11]Qing Wang; Chuang-Yuan Chang; Long-Xing Shi, "Design of adaptive fuzzy logic controller for auto-adjustable DC-DC converters," Solid-State and Integrated Circuit Technology (ICSICT), 2010 10th IEEE International Conference on, 1-4 Nov. 2010, pp. 469-471. 